\title{
THE CIRCULATION TIME AS A CLINICAL TEST
}

\author{
BY \\ H. KOPELMAN \\ From the Department of Medicine, The Postgraduate Medical School of London \\ Received August 14, 1950
}

Since Harvey's discovery of the circulation, the velocity of blood flow and its later clinical counterpart, the circulation time, have occupied the thoughts of many workers. The methods used have been as ingenious and diverse as the explanations and hypotheses drawn from them. The result has been that the problem has become more complex and even confused, so that the circulation time as such, has only limited clinical value. Numerous papers that correlate circulation time with other features of cardiac failure have appeared, but their value has been somewhat reduced since many of these other features were but little understood. In view of the more recent work on cardiac output and on the hæmodynamics of the circulation a reinvestigation of circulation time was undertaken.

Although Spier, Wright, and Saylor (1936) recognize the requirements of an ideal substance for estimation of circulation time, such a substance has still to be discovered. Subjective tests have the disadvantage of requiring the intelligent co-operation of the patient. Many of the objective tests involve the peripheral circulation which introduces complications due to the considerable variations in this part of the vascular system. The arrival of tracer substances or concentrated salt solutions at a given point in the circulation may be recognized by objective physical methods, but the apparatus necessary prohibits their routine use. The gasp following the injection of sodium cyanide, 5 to $10 \mathrm{mg}$. in a 2 per cent solution (Robb and Weiss, 1932) appeared to be a satisfactory objective test. In normals it gave a sharp end point which could be recorded, but in cardiac failure the dose had to be increased to an extent that was considered unsafe. It has been shown by Ruskin and Rockwell (1945) and Robb and Weiss (1934) that suboptimal doses of all substances can prolong the circulation time, as can small volumes of the injected material. However, once the optimal concentration and volume is reached, further additions do not shorten the time. Artificial prolongation of the time was found to occur frequently with sodium cyanide in cardiac failure, because the volume injected was small and the dose used was often found to be minimal.

\section{METHODS AND MATERIAL}

The difficulties due to dilution of small doses, were found to be avoided by using saccharine, $2.5 \mathrm{gm}$. in $4 \mathrm{ml}$. of sterile water, given rapidly in 1 to $2 \mathrm{sec}$. through a wide bore needle (Fishberg et al., 1933). This substance was therefore selected for routine circulation time estimations. It gave a constant and satisfactory end point in practically all cases of cardiac failure and was not associated with any unpleasant effects. It was given with the patient in the semi-recumbent position, the arm for injection resting on a pillow at the side of the body. The opposite arm was raised and was dropped by the patient as soon as the sweet taste was appreciated. The only disadvantage of the solution used was occasional local venous thrombosis. Saccharine was used in preference to sodium dehydrocholate, as unpleasant sequelæ have been reported with this substance (Norman, 1947).

In view of the suspected relationship between prolongation of the circulation time and congestive changes in the lungs, vital capacity measurements were made with a portable spirometer. In the 
absence of primary lung disease such as emphysema, depression of the vital capacity may be taken as reflecting in some degree the consequences of pulmonary congestion resulting from left-sided heart failure.

Cases selected for study all showed features of cardiac failure in varying degree. Some or all of the following features were present-dyspnœa at rest, raised jugular venous pressure, moist sounds in the lung bases, peripheral œdema, and tender palpable liver. The circulation time and vital capacity were determined as soon as possible after admission, but in a few cases where the condition of the patient was poor, the investigations were necessarily delayed until there was some improvement. The tests were repeated at approximately weekly intervals, the " final " figures being those taken after the clinical evidence of failure had reached its maximum improyement.

\section{Changes in Circulation Time and Vital Capacity before and after Treatment}

It was found that the cases could be arranged into three main groups which showed the following features.

Group I. This comprised cases of uncomplicated congestive failure and included cardiac failure due to hypertension, ischæmic heart disease, and chronic rheumatic valvular disease. They showed a prolonged circulation time and reduced vital capacity. After treatment and improvement, the circulation time progressively fell as the vital capacity increased. However, in many of this group the circulation time fell to only a high normal level (Table I). There were three cases in which,

TABLE I

Circulation Time and Vital Capacity in UnComplicated Congestive Heart Failure before and after TREATMENT (GROUP I)

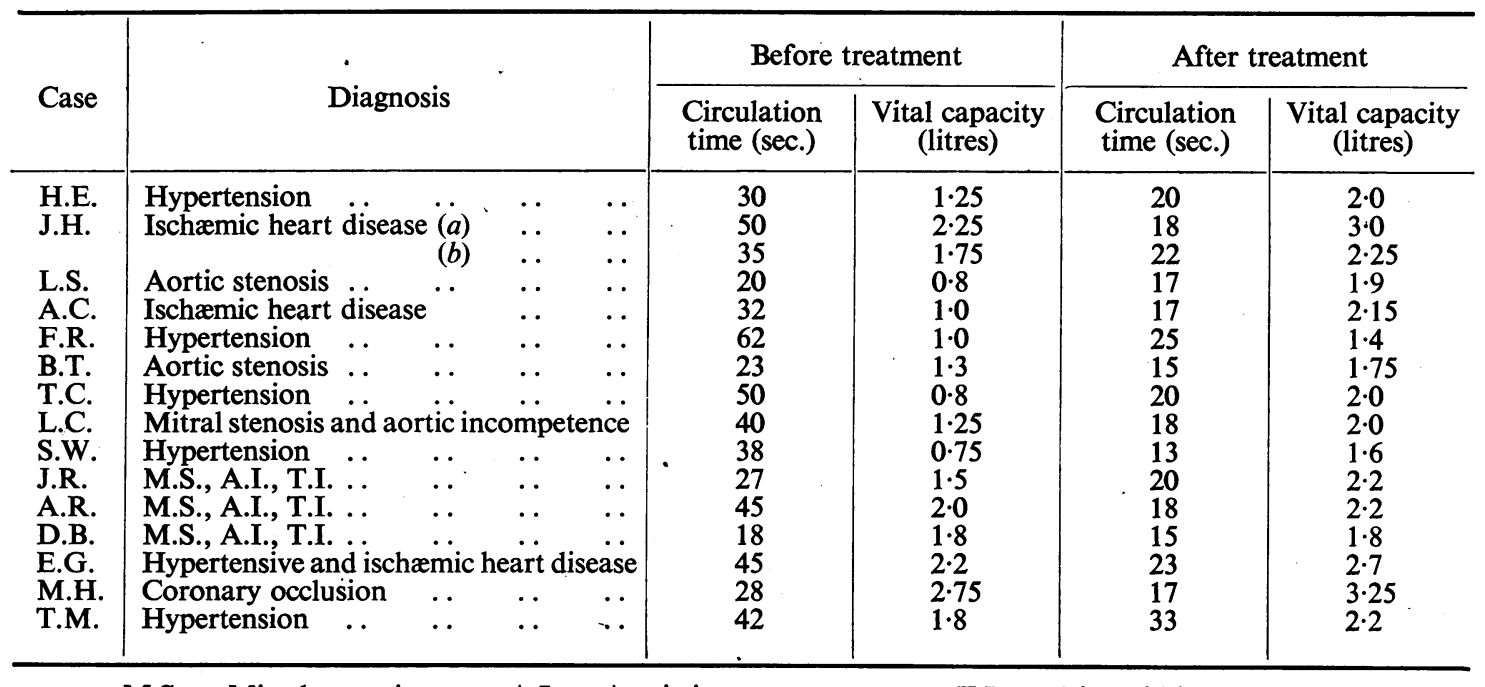

$$
\text { M.S. }=\text { Mitral stenosis. } \quad \text { A.I. }=\text { Aortic incompetence } \quad \text {, T.I. }=\text { Tricuspid incompetence. }
$$

although there was reduction in the circulation time to high normal levels, there was little increase in vital capacity. These were all instances in which tricuspid incompetence or stenosis was present, or in which both were present, in addition to mitral and aortic disease (two cases since confirmed by autopsy). All these patients showed enormous hearts even after improvement, while chest radiographs and cardioscopy were remarkable for the absence of pulmonary congestion.

Group II. Here the patients gave long histories of recurrent and chronic bronchitis and had clinical evidence of emphysema or pulmonary fibrosis. About half were complicated by hyper- 
tension. This group showed that although initially there might be some increase in the circulation time there was a marked reduction in the vital capacity. With improvement, the circulation time fell rapidly to a low normal value, but the vital capacity showed little or no rise (Table II).

TABLE II

Circulation Time and Vital Capacity in Chronic Pulmonary Disease before and after Treatment (GROUP II)

\begin{tabular}{|c|c|c|c|c|c|}
\hline \multirow[b]{2}{*}{ Case } & \multirow[b]{2}{*}{ Diagnosis } & \multicolumn{2}{|c|}{ Before treatment } & \multicolumn{2}{|c|}{ After treatment } \\
\hline & & $\begin{array}{l}\text { Circulation } \\
\text { time (sec.) }\end{array}$ & $\begin{array}{c}\text { Vital capacity } \\
\text { (litres) }\end{array}$ & $\begin{array}{l}\text { Circulation } \\
\text { time (sec.) }\end{array}$ & $\begin{array}{c}\text { Vital capacity } \\
\text { (litres) }\end{array}$ \\
\hline $\begin{array}{l}\text { F.H. } \\
\text { A.D. } \\
\text { F.B. }\end{array}$ & $\begin{array}{l}\text { Emphysema } \\
\text { Emphysema and hypertension } \ldots \\
\text { Bronchitis; emphysema, and hyper- } \\
\text { tension. }\end{array}$ & $\begin{array}{l}15 \\
60 \\
27\end{array}$ & $\begin{array}{l}0.5 \\
1.0 \\
1.1\end{array}$ & $\begin{array}{l}10 \\
13 \\
12\end{array}$ & $\begin{array}{l}1.5 \\
1.25 \\
1.2\end{array}$ \\
\hline $\begin{array}{l}\text { W.G. } \\
\text { A.S. } \\
\text { A.G. } \\
\text { A.F. } \\
\text { W.H. } \\
\text { E.O. }\end{array}$ & $\begin{array}{l}\text { Chronic bronchitis and hypertension.. } \\
\text { Bronchitis and ischæmic heart disease } \\
\text { Pulmonary fibrosis } \\
\text { Emphysema and bronchitis .. } \\
\text { Emphysema (severe) and bronchitis ... } \\
\text { Hypertension, bronchitis, and anæmia }\end{array}$ & $\begin{array}{l}20 \\
14 \\
13 \\
19 \\
15 \\
12\end{array}$ & $\begin{array}{l}0.5 \\
2 \cdot 2 \\
1.65 \\
1.1 \\
0.5 \\
1.0\end{array}$ & $\begin{array}{l}10 \\
11 \\
13 \\
14 \\
10 \\
11\end{array}$ & $\begin{array}{l}0 \cdot 6 \\
2 \cdot 25 \\
1.70 \\
1 \cdot 5 \\
1.5 \\
1.25\end{array}$ \\
\hline
\end{tabular}

Group III. In this group, there were four cases of acute glomerular nephritis of which three showed some initial mild hypertension, a patient with acute rheumatism whose chest X-ray was compatible with "rheumatic pneumonia," and a case of acute uræmia following anuria due to a concealed accidental hæmorrhage, with subsequent recovery after Cæsarian section.

The circulation time was normal or only slightly prolonged; the vital capacity was, however, reduced in all cases. With improvement the circulation time remained normal, or in one in which it was raised, rapidly became normal. The vital capacity rose to its presumed previous level (Table III).

TABLE III

Circulation Time and Vital Capacity in Miscellaneous Circulatory Disorders before and after TREATMENT

\begin{tabular}{|c|c|c|c|c|c|c|c|}
\hline \multirow[b]{2}{*}{ Case } & \multirow{2}{*}{\multicolumn{3}{|c|}{ Diagnosis }} & \multicolumn{2}{|c|}{ Before Treatment } & \multicolumn{2}{|c|}{ After Treatment } \\
\hline & & & & $\begin{array}{l}\text { Circulation } \\
\text { time (sec.) }\end{array}$ & $\begin{array}{l}\text { Vital capacity } \\
\text { (litres) }\end{array}$ & $\begin{array}{l}\text { Circulation } \\
\text { time (sec.) }\end{array}$ & $\begin{array}{l}\text { Vital capacity } \\
\text { (litres) }\end{array}$ \\
\hline $\begin{array}{l}\text { A.K. } \\
\text { L.S. } \\
\text { W.B. } \\
\text { D.M. } \\
\text { A.B. } \\
\text { M.S. }\end{array}$ & $\begin{array}{l}\text { Acute nephritis . } \\
\text { Acute rheumatic lung } \\
\text { Acute nephritis .. } \\
\text { Acute nephritis .. } \\
\text { Uræmic lung } . . \\
\text { Acute nephritis .. }\end{array}$ & $\begin{array}{l}. \\
\because \\
\because \\
\because \\
.\end{array}$ & $\begin{array}{l}. . \\
\because . \\
\because \\
.\end{array}$ & $\begin{array}{l}25 \\
12 \\
15 \\
17 \\
13 \\
12\end{array}$ & $\begin{array}{l}1.5 \\
1.2 \\
2.5 \\
1.7 \\
1.25 \\
2.5\end{array}$ & $\begin{array}{l}15 \\
10 \\
15 \\
15 \\
13 \\
12\end{array}$ & $\begin{array}{l}3 \cdot 0 \\
2.5 \\
3.75 \\
2 \cdot 5 \\
2 \cdot 25 \\
3.75\end{array}$ \\
\hline
\end{tabular}

These cases consisted mainly of previously healthy young adults who presented with dyspnœa, some rise in jugular venous pressure, and X-ray appearances similar to those of pulmonary venous congestion. 


\section{Changes in Heart Size and Circulation Time}

Changes in heart size were determined by comparison of the ratio $\frac{\text { Transverse diameter of heart }}{\text { Internal diameter of chest }}$ during failure and later during improvement. The transverse diameter of the heart was taken as the sum of the distances from the mid-line to the outermost right and left borders of the heart. The internal diameter of the chest was measured at the level of the fourth costochondral junction. All measurements were in centimetres and were taken from teleroentgenograms. The upper limit of normal for this ratio has been taken as 0.54 (Meneely and Chesnut, 1947).

It can be seen that considerable reduction in the arm to tongue circulation time can occur with little change in the cardiothoracic ratio (Table IV). Although this ratio may remain much higher than the accepted normal, the circulation time may be within normal limits.

TABLE IV

Changes in Heart Size and Circulation Time Resulting from Treatment of Heart failure

\begin{tabular}{l|l|l|c|c|c|c}
\hline & \multicolumn{3}{|c|}{ In failure } & \multicolumn{3}{|c}{ After treatment } \\
\cline { 2 - 6 } Case & $\begin{array}{c}\text { Trans. diam. heart } \\
\text { Trans. diam. chest }\end{array}$ & Ratio & $\begin{array}{c}\text { Circulation time } \\
\text { (sec.) }\end{array}$ & $\begin{array}{c}\text { Trans. diam. heart } \\
\text { Trans. diam. chest }\end{array}$ & Ratio & $\begin{array}{c}\text { Circulation time } \\
\text { (sec.) }\end{array}$ \\
\hline S.W. & $\frac{16 \mathrm{~cm} .}{24 \mathrm{~cm} .}$ & 0.66 & 38 & $\frac{14 \mathrm{~cm} .}{23 \mathrm{~cm} .}$ & 0.61 & 13 \\
\hline L.C. & $\frac{15 \cdot 25}{25 \cdot 75}$ & 0.59 & 40 & $\frac{15 \cdot 25}{25 \cdot 5}$ & 0.59 & 18 \\
\hline T.C. & $\frac{16.5}{24}$ & 0.66 & 50 & $\frac{16 \cdot 5}{25}$ & 0.65 & 20 \\
\hline F.R. & $\frac{18}{24}$ & 0.75 & 62 & $\frac{16}{23}$ & 0.70 & 25 \\
\hline A.C. & $\frac{17}{24.5}$ & 0.69 & 32 & $\frac{17}{24}$ & 0.64 & 17 \\
\hline J.H. & $\frac{18}{25}$ & 0.72 & 50 & $\frac{17}{25}$ & 0.68 & 18 \\
\hline J.H. & $\frac{19 \cdot 3}{25.2}$ & 0.76 & 35 & $\frac{19 \cdot 4}{25 \cdot 2}$ & 0.76 & 22 \\
\hline D.B. & $\frac{18}{22.5}$ & 0.80 & 17 & $\frac{18}{22.5}$ & 0.80 & 15 \\
\hline B.T. & $\frac{11}{22.5}$ & 0.49 & 23 & $\frac{11}{22}$ & 0.50 & 15 \\
\hline
\end{tabular}

Comparison of Arm-Tongue and Heart-Tongue Times and of the Circulation Time With the Minute CaRdiac OUTPUT

Opportunity was taken in cases being investigated by cardiac catheterization to compare the arm to tongue circulation time with that of the heart to tongue time. The latter was determined by injecting the saccharine solution through the cardiac catheter into the right auricle and noting the time required to appreciate the taste. In 11 cases so investigated it was found that the difference 
between the arm to tongue, and the right heart to tongue times varied between 3 to $6 \mathrm{sec}$. and was. not related to the right auricular pressure measured by means of a saline manometer.

In 18 cases the minute cardiac output was determined by the Fick principle and compared with the arm to tongue circulation time. It appears that with normal circulation times the minute cardiac output is higher than in those cases where the circulation time is prolonged (Table $\mathrm{V}$ and Fig. 1).

TABLE V

Relationship between Circulation Time and Cardiac Output

\begin{tabular}{|c|c|c|c|c|c|}
\hline \multicolumn{3}{|c|}{ 1. Normal circulation time } & \multicolumn{3}{|c|}{ 2. Prolonged circulation time } \\
\hline & $\begin{array}{l}\text { Circulation } \\
\text { time (sec.) }\end{array}$ & $\mid \begin{array}{c}\text { Cardiac } \\
\text { output } 1 / \mathrm{m}\end{array}$ & & $\begin{array}{l}\text { Circulation } \\
\text { time (sec.) }\end{array}$ & $\mid \begin{array}{c}\text { Cardiac } \\
\text { output } 1 / \mathrm{m}\end{array}$ \\
\hline $\begin{array}{l}\text { Emphysema and chronic cor } \\
\text { pulmonale. }\end{array}$ & 16 & $7 \cdot 4$ & Bronchitis and hypertension & 23 & $7 \cdot 5$ \\
\hline Acute nephritis & 18 & $5 \cdot 8$ & M.S. and A.I. & 40 & $1 \cdot 75$ \\
\hline A.I. and myxœdema $\ldots$ & 17 & $5 \cdot 0$ & Ischæmic heart disease & 50 & $3 \cdot 1$ \\
\hline M.S. (compensated) $\quad \ldots \quad \ldots$ & 14 & $7 \cdot 2$ & Hypertensive heart disease .. & 38 & $4 \cdot 6$ \\
\hline $\begin{array}{lll}\text { Cor pulmonale. . } \quad \ldots & \ldots\end{array}$ & 13 & $6 \cdot 4$ & Hypertension and emphysema & 27 & $2 \cdot 2$ \\
\hline Mitral stenosis and anæmia ... & 15 & $5 \cdot 2$ & $\begin{array}{l}\text { Hypertension and ischæmic } \\
\text { heart disease. }\end{array}$ & 40 & $2 \cdot 8$ \\
\hline $\begin{array}{l}\text { Emphysema, bronchitis, cor } \\
\text { pulmonale. }\end{array}$ & 16 & $10 \cdot 0$ & Malignant hypertension & 26 & $2 \cdot 1$ \\
\hline Emphysema and polycythæmia & 15 & $3 \cdot 8$ & $\begin{array}{l}\text { Rh. heart disease, M.S., and } \\
\text { A.I. }\end{array}$ & 43 & $2 \cdot 8$ \\
\hline Acute nephritis & 15 & $7 \cdot 2$ & A.I., M.S., and T.I. .. & 25 & 1.9 \\
\hline
\end{tabular}

M.S. = Mitral stenosis.

A.I. $=$ Aortic incompetence.

T.I. = Tricuspid incompetence.

The circulation time determined by the usual technique may be affected by delay in the venous return to the heart, in the arterial channel, and finally in the appreciation of the taste sensation itself. From the above it appears that delay on the venous side even when the venous pressure is much raised, probably plays only a small part in the prolongation of the circulation time. Delay on the arterial side and in the appreciation of the taste must also be but a small factor with marked prolongation of the circulation time. The longer times in elderly patients, noted by many workers, may be due to delay in taste perception. For these reasons the normal range for saccharine circulation time was extended up to 18 sec.

\section{Discussion}

Much prolongation of the circulation time has usually been accepted as being indicative of congestive heart failure of whatever ætiology (Tarr, Oppenheimer, and Sage, 1932). Blumgart and Weiss (1928) regarded the pulmonary circuit as the main site of delay in the velocity of the blood flow. They state, that in cardiovascular disease there is a striking tendency for a decrease in vital capacity of the lungs to be associated with an increase in the pulmonary circulation time, denoting a slower speed of blood flow through the lungs. Of more recent years, Gernandt and Nylin (1946) and Nylin (1945) have studied the volume of, and changes in, the residual blood of the heart and the dilution curve of activity in arterial blood after intravenous injection of radioactively labelled corpuscles. They showed statistically a correlation between heart volume, i.e. the amount of residual 


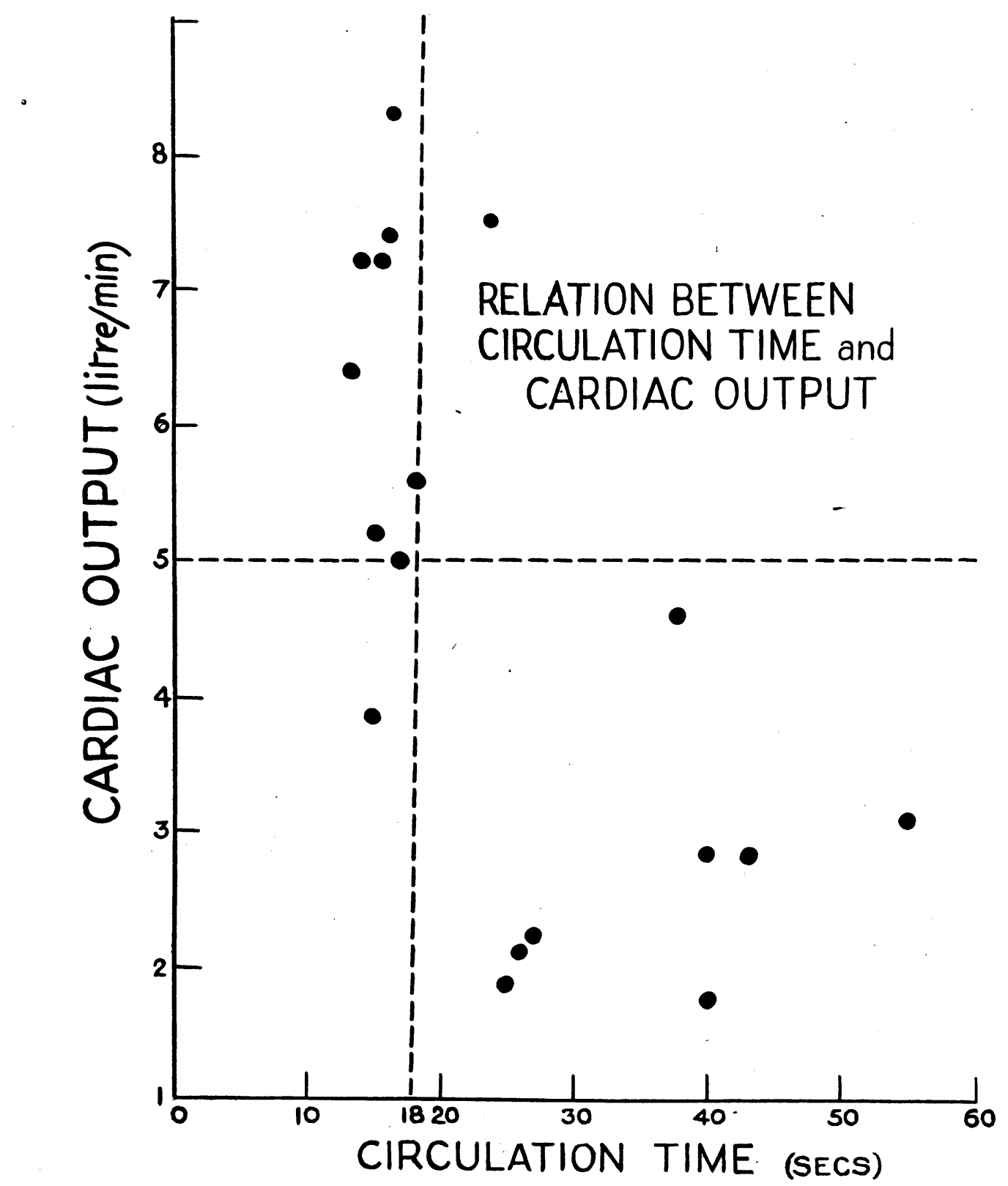

Fig. 1.-The relation between the cardiac output and the arm to tongue circulation time in 18 patients.

blood, and the circulation time (correlation coefficient, $0 \cdot 51$ ). The greater the residual blood, the longer the delay in the heart, and thus the longer will the test substance take to reach the taste buds. Nathanson and Elek (1947) also found a statistically significant correlation between heart size and circulation time. Meneely and Chesnut (1947), however, conclude that the circulation time is proportional to the relative heart volume in patients with heart disease-not to residual blood which is an expression of dilution. They do not agree that the residual blood delays the circulation time but believe that there is associated impaired myocardial function. 
In emphysema and other causes of chronic pulmonary insufficiency it is generally agreed that the circulation time (arm to tongue) is normal (Blumgart, 1931; Oppenheimer and Hitzig, 1936; Gross, 1945) even when associated with right ventricular enlargement. Prolongation of the circulation time in these conditions is taken as being indicative of complicating myocardial failure (Gillanders, 1949). However, Taquini et al. (1948) observed that severe pulmonary emphysema and fibrosis with pronounced polycythæmia, resulted in prolonged circulation time when no heart failure was present. In our experience polycythæmia is an unusual complication of pulmonary fibrosis and emphysema, and in one case (W.H., Table II) who showed marked polycythæmia with a twice normal blood viscosity (in vitro), there was a rapid circulation time throughout his stay in hospital.

The data presented indicate that the factors involved are probably complicated and may vary from case to case. These factors may be dilatation of the cardiac chambers, the volume of the pulmonary vascular bed, and the cardiac output especially in relation to these relative volumes. An increase in either the cardiac volume or in the pulmonary vascular bed might be compensated by an increase in cardiac output, so that the resultant circulation time may be unchanged and conversely a diminution of the cardiac output, with no change in the pulmonary vascular bed, would prolong the circulation time.

In Group I there was an apparent relationship between the shortening circulation time and increasing vital capacity. The cardiac output was variable but usually low. Amongst this group were instances in which there was no radiological evidence of cardiac enlargement even when in failure, and others in which although the heart was large even after improvement, there was a normal circulation time. In some cases of cardiac enlargement serial X-rays showed little measurable reduction after improvement. Prolonged circulation times have been noted by others without great cardiac enlargement (Gross, 1945). Although with improvement there was a progressive increase in vital capacity with a corresponding diminution in the circulation time, the tendency in this group was to have a circulation time that was on the high side of normal even after clinical evidence of failure had subsided.

The cases in Group II had as a common basic feature chronic lung disease, which in itself was primarily responsible for the diminished vital capacity. When heart failure develops, pulmonary capillary congestion is not a necessary accompaniment, as rising pulmonary arterial pressure is the main cause of the strain (Cournand, 1947). The insignificant change in vital capacity is therefore to be expected. The circulation time is frequently within normal limits and in keeping with the observation that the cardiac output in such patients tends to be normal or raised (Richards, 1945; Stead et al., 1948). In gross failure, however, in such patients, the circulation time may be prolonged, and it has been shown that in advanced failure the minute cardiac output may fall to low levels (Howarth et al., 1947).

Group III consists of cases who showed a special variety of pulmonary congestion occurring par excellence in uræmia with hypertension, but also in acute nephritis and acute cardiac rheumatism. It is peculiar in its radiological, histological, and clinical features (Doniąch, 1947). Dyspnœa may be much less intense than in other comparable types of pulmonary congestion due to cardiac causes. The mechanism at work in the production of these cases is obscure and these circulation time studies merely serve to point out a further difference from more ordinary types of pulmonary congestion.

It has been shown that delay in the circulation time can occur with normal sized hearts, and conversely there may be no delay with grossly enlarged hearts. Although this does not exclude cardiac dilatation as a factor in causing delay, it is unlikely to be the main one. It appears more probable that the major portion of circulation time is occupied in passage through the pulmonary vasculature. The mean pulmonary circulation time is dependent on the relationship between the cardiac output and the volume of the pulmonary vascular bed. In the various conditions, changes in either may predominate or both play some part. Thus, left ventricular failure may lead to pulmonary congestion, and so both factors would tend to prolong the circulation time. It is in these conditions (Group I) that the greatest prolongation occurred. The accompanying reduction in the vital capacity in this group suggests the presence of an increase in the pulmonary vascular 
bed, but other factors such as œdema, hydrothorax and cardiac enlargement may also play some part in reducing the vital capacity.

In Group II there is no marked prolongation in circulation time until the previously high cardiac output falls and it is probable that this fall in minute cardiac output is the main cause for any pro-. longation. Thus, there is no increase in the arm to tongue time until the heart fails to maintain the high output initially demanded by the respiratory disability.

The special pulmonary congestion seen in Group III may only initially show an increase in the circulation time, which rapidly returns to normal. Although the cause of this is not quite clear, it is possibly connected with some transient increase in pulmonary vascular pressure which together with some pulmonary capillary dysfunction gives rise to a highly fibrinous alveolar transudate and special radiological appearances (Doniach, 1947).

\section{SUMmary}

The circulation time using saccharine solution and the vital capacity have been estimated in cases presenting features of congestive cardiac failure and have been repeated during recovery.

Our patients could be divided into.three groups depending on the changes that occurred in the circulation time and vital capacity.

These groups consisted of (i) instances of uncomplicated congestive cardiac failure; (ii) cases complicated by chronic respiratory disease; and (iii) a special group typically seen in acute nephritis and uræmia.

Comparison of the circulation time with the cardiac output and the heart size has been made. The parts played by the cardiac output, cardiac size, pulmonary vascular bed, and pulmonary œdema have been discussed in relation to the changes occurring in these groups.

It is emphasized that all these factors must be taken into account to determine the significance of the circulation time. Serial readings of the circulation time and the vital capacity by differentiating cases into the groups described help to evaluate the relative parts played by these factors and their underlying cause.

I should like to express my gratitude to Professor John McMichael for his help and advice in preparing this paper.

\section{REFERENCES}

Blumgart, H. L. (1931). Medicine, 10, 1.

-, and Weiss, S. (1928). J. Clin. Invest., 5, 379.

Cournand, A. (1947). New York Acad. Med., 23, 27.

Doniach, I. (1947). Amer. J. Roentgenol., 58, 620.

Fishberg, A. M., Hitzig, W. M. and King, F. H. (1933). Proc. Soc. Exper. Biol. \& Med., $30,651$.

Gernandt, B., and Nylin, G. (1946). Amer. Heart J., 32, 411.

Gillanders, A. D. (1949). Quart. J. Med., 18, 263.

Gross, D. (1945). Amer. Heart J., 30, 19.

Howarth, S., McMichael, J., and Sharpey-Schafer, E. P. (1947). Clin. Sci., 6, 187.

Meneely, G. R., and Chesnut, J. L. (1947). Amer. Heart J., 33, 175.

Nathanson, M. H., and Elek, S. R. (1947). Ibid., 33, 464

Norman, J. K. (1947). Ibid., 34, 740.

Nylin, G. (1943). Ibid., 25, 598.

(1945). Ibid., 30, 1.

Oppenheimer, B. S., and Hitzig, W. M. (1936). Ibid., 12, 257.

Richards, D. W., Jr. (1945). Federation Proc., 4, 215.

Robb, G. P., and Weiss, S. (1932). A Amer. Heart J., 8, 650.

(1934). Ibid., 9, 742.

Ruskin, A., and Rockwell, P. (1945). Proc. Soc. Exper. Biol. \& Med., 60, 40.

Spier, L. C., Wright, I. S., and Saylor, L. (1936). Amer. Heart J., 12, 511.

Stead, E. A., Warren, J. V., and Brannon, E. S. (1948). Arch. intern. Med., 81, 282.

Taquini, A. C., Fasciolo, J. C., and Savrig, T. R. E. (1948). Ibid., 82, 535.

Tarr, L., Oppenheimer, B. S., and Sage, R. V. (1932). Amer. Heart J., 8, 766. 